\title{
REAL EXPOSURE: FIELD MEASUREMENT OF CHEMICAL PLUMES IN HEADWATER STREAMS
}

David D. Edwards

\begin{abstract}
A Thesis
Submitted to the Graduate College of Bowling Green

State University in partial fulfillment of the requirements for the degree of
\end{abstract}

MATER OF SCIENCE

August 2014

Committee:

Paul A. Moore, Advisor

Robert Pillsbury

Shannon Pelini 
(C) 2014

David D. Edwards

All Rights Reserved 


\section{ABSTRACT}

Paul A. Moore, Advisor

In fluvial systems, organismic exposure to nonpoint source pollutants will fluctuate in frequency (exposure events), intensity (concentration), and duration. The reliance on lethal concentrations and static exposure in many laboratory studies does not adequately represent nor address exposure to in situ chemical plumes of fluvial habitats. In order to adequately address field exposure in a lab setting, one needs an understanding of the physics of chemical transmission within moving fluids. Because of the chaotic nature of turbulence, chemical plumes introduced to fluvial systems have a spatial and temporal microstructure with fluxes in chemical concentration. Consequently, time - averaged static exposure models are not ecologically relevant for the major reason of in situ distribution. The purpose of this study was to quantify in situ chemical distribution and dispersion within two physically different streams. Dopamine was introduced as a chemical tracer mimicking groundwater runoff. Chemical fluxes and stream hydrodynamics were simultaneously measured using a microelectrode and an acoustic doppler velocimeter (ADV), respectively, at three heights of three downstream locations at each research site. Fine - scale measurements of the dopamine plume microstructure showed organisms could be exposed to chemical fluctuations where concentrations are significantly greater than the overall time - averaged concentration. These measurements demonstrate that rather than relying on static exposure, standards for pollution need to consider the concept of exposure being interdependently linked to flow of the fluid medium. The relationship between fluid dynamics, pollution exposure and organism physiology are complex and need to be evaluated in ways to mimic natural systems. 


\section{ACKNOWLEDGMENTS}

This work would not be possible without the continued support and encouragement from numerous individuals and groups. I would like to first and foremost thank my advisor, Paul Moore, for his invaluable guidance, patience, and leadership with continual strive for excellence. Paul has taught me how to think like a scientist as a more strategically and intellectually aware individual. For that, in addition to his scientific knowledge and mentorship, I am forever in debt.

I would also like to thank my committee members Robert Pillsbury of University-

Wisconsin Oshkosh and Shannon Pelini of Bowling Green State University. My educational and scientific career would not have routed through Bowling Green State University without Dr. Pillsbury's willingness to work with me on both a collaborative research project and teaching general ecology at the University of Michigan Biological Station. Moreover, Dr. Pelini has been insurmountable in realizing the potential for other applications of this project. She has offered great advice, support, and input for what being a great scientist and role model in your field is like.

Additionally, I would like to gratefully thank the University of Michigan Biological Station for ADV equipment and funding support (J.B. \& Marilyn McKenzie Graduate Student Fund) used during this study. The entire UMBS community provided facilities and an atmosphere that helps build the integrity of biological sciences. A special thank you is extended to Ana Jurcak for always being there when the going got tough and for the many discussions we've had throughout the last two years. Moreover, thank you to all members (past and present) of the Lab for Sensory Ecology at Bowling Green State University for ideas, comments, and suggestions throughout all phases of this work.

Last but not least, thank you to my parents, DeWayne and Nancy Edwards, and my brother, Daniel, who have supported me from the beginning. DeWayne for instilling in me the 
hardest work ethic and showing persistence can make all the difference. Thank you, Nancy, for having such a caring, kind heart and instilling an appreciation for others within my own mindset. Their encouragement and continued love from the goodness of their hearts has added to the determination for completion of this project. Growing up in the outdoors along the Fox River, has profoundly impacted my career choice and development into the person I am today. I am forever grateful for them. 


\section{TABLE OF CONTENTS}

Page

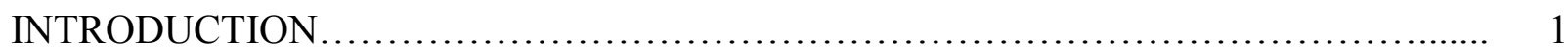

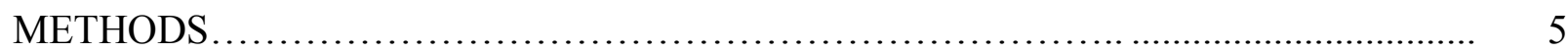

Study sites....................................................... 5

Chemical tracer delivery protocol........................................ 5

Sampling protocol..................................................... 6

Turbulence measurements............................................. 6

Chemical tracer measurements.......................................... 7

Data analysis..................................................... 8

Flow data.......................................................... 8

Chemical plume data.......................................... 10

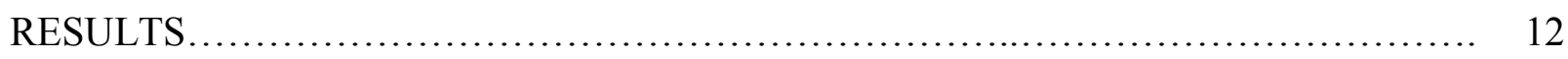

Hydrodynamics.................................................... 12

Velocity profiles............................................... 12

Fine - scale plume structure ......................................... 12

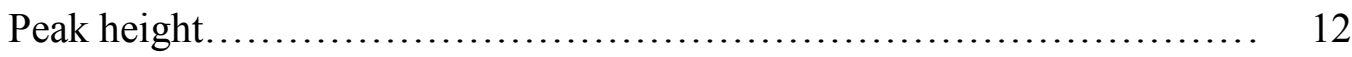

Slope..................................................... 13

Peak to mean ratio............................................... 13

Intermittency.............................................. 14

Peak length................................................... 14

Time above average......................................... 14

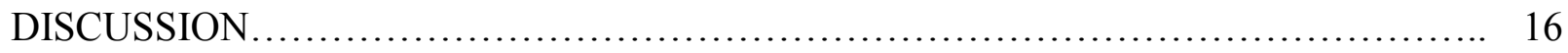


Chemical plumes and hydrodynamics................................... 16

A new concept of exposure................................................. 18

Time-series exposure............................................ 19

Conclusions ........................................................... 22

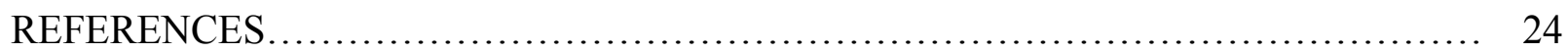

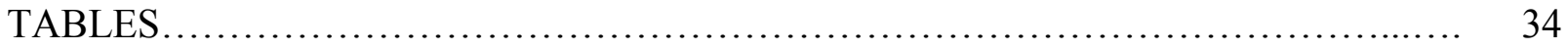

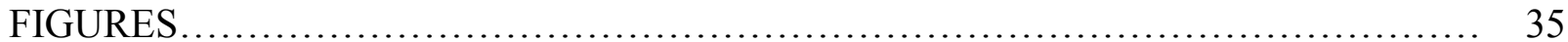




\section{LIST OF TABLES AND FIGURES}

Table

Page

1 Hydrodynamic characterization of Carp Creek and Carp Lake River

2 Hydrodynamic characterization of the benthic boundary layer of Carp Creek and Carp

Lake River.

Figure

1 Aerial photograph of Carp Lake River and Carp Creek location within Emmett, County

MI, USA ............................................................. 35

2 Schematic set - up of field sampling locations at Carp Creek and Carp Lake River 36

$3 \quad$ Power spectral analysis of time - series flow velocity data................................ 37

4 Canonical plot of linear discriminant analysis.............................. 38

$5 \quad$ Peak height, peak slope, and percent time above average ................................... 39

$6 \quad$ Peak to mean, intermittency, and peak length ................................................... 40 


\section{INTRODUCTION}

Aquatic ecotoxicology has expanded rapidly during recent years due in part to the increased awareness of the episodic exposure by aquatic biota to pollutants from nonpoint sources (Zhao and Newman 2006; Wang 2011). Traditional ecotoxicology studies have relied on exposing individual organisms to a static concentration for a specified length of time (Ashauer et al. 2006; Diamond et al. 2006; Butcher et. al 2006; Gordon et. al 2012). In addition, current ecotoxicity models and U.S. Environmental Protection Agency (EPA) water impairment criteria largely rely on deleterious effects of static exposure with reference to lethal concentrations (i.e. LC20, LC50) (USEPA 2004; 2013). Yet these measurements that are collected from the field and referenced to utilize in static laboratory studies only allow a 'snapshot' capture of a chemical concentration within a fluvial system. Exposure to pollutants from nonpoint sources will typically fluctuate in frequency (exposure events), intensity (concentration), and duration at various scales of interest. Consequently, deleterious effects are defined as interacting degrees of frequency, intensity, and duration (Gordon et al. 2012).

Recent research has attempted to incorporate this episodic exposure paradigm to evaluate toxic effects of a chemical through modeling pulsed exposure events at various concentrations coupled with the recovery timing of organisms from deleterious effects (Butcher et al. 2006; Sandahl et al. 2006; Hoang et al. 2007; Earl and Whiteman 2009). Laboratory studies have also focused on establishing specific sub - lethal concentrations of exposure at various time averaged static concentrations with some behavioral or physiological end point measurement (Diamond et al. 2005; Diamond et al. 2006; Earl and Whiteman 2009; Wang 2011). However, as Ashauer et al. (2006) expresses, there is a generality of assuming a linkage between lab data, which current exposure models are based on, and real - time exposure in the field. Aquatic 
ecotoxicology research today is lacking any real time - series analysis of exposure at a high resolution scale for greater ecological and biological significance. The reliance on time averaged static exposure to concentrations in many laboratory studies is consequently not ecologically relevant in aquatic habitats for the major reason of in situ distribution.

Animal orientation behavior has elucidated the interdependency between hydrodynamics and chemical plume structure (Finelli 2000; Moore and Crimaldi 2004). Chemical plumes are now widely accepted as having a 'patchy' distribution rather than a stable gradient as previously predicted by time - averaged (Gaussian) models (Murlis and Jones 1981; Moore and Atema 1988, 1991; Finelli et al. 1999; Finelli 2000; Moore and Crimaldi 2004; Webster and Weissburg 2009; Wolf et al. 2009; Weissburg 2011). The degree of 'patchiness' and chemical dispersal is largely dictated by turbulence (Denny 1993; Vogel 1994) and is habitat specific (Moore et al. 2000; Wolf et al. 2009). Unfortunately, much of our current knowledge about the dispersal of chemical plumes at a scale of ecological relevance is limited to pristine laboratory flume studies (Weissburg and Zimmer-Faust 1994; Finelli et al. 1999; Finelli 2000; Moore et al. 2000; Wolf et al. 2004; 2009; Sanford 1997). Flume studies often limit the study of scalar transport for chemical exposure downstream as flow regimes are greatly influenced by the physical characteristics of the habitat (Roy et al. 2004; Buffin - Bélanger et al. 2006; Shen and Diplas 2008). Gravel or cobble substrates contain much larger roughness elements than sand substrates which alter the degree and type of mixing (patchiness) associated with chemical plumes (Moore et al. 2000; Wolf et al. 2009).

Chemical plumes moving through a lotic system are dispersed on substrates in response to the deterministic, chaotic flow at the benthic level (Moore and Grills 1999; Finelli 2000; Moore and Crimaldi 2004; Wolf 2009). The turbulence created from the flow regime interacting 
with the physical characteristics of the habitat actively stir and mix a chemical constituent as the chemical plume evolves downstream with the unidirectional flow (Webster and Weissburg 2009). Mode of introduction will affect the in situ plume structure and subsequent exposure of an organism to a chemical downstream. A very large percentage of anthropogenic chemical stream input occurs through sub - surface runoff providing a linkage to the surrounding landscape.

The influx of precipitation water with different chemistry is coupled to the hydrology of the aquatic habitat (Li and Sivalpalan 2011). Runoff pathways from the surrounding landscape are distinguished and established by various degrees of soil saturation with the interaction of flow path and travel time (Doležal and Kvítek 2004). One subsurface pathway, known as interflow, comprises storm water soil infiltration with a high potential for chemical transport and reappearance in surface waters (Doležal and Kvítek 2004). As defined by Flügel (1993), interflow is the seepage of rainwater, which infiltrates and percolates through soil profiles, downslope into a river or stream. Moreover, this pathway can be identified as shallow subsurface flow from a perched water table. Interflow is partitioned from other subsurface runoff by reaching the downslope body of water before entering the groundwater aquifer. In sloping hilly areas, interflow is also an important component of baseflow recharge within soils of high porosity (Barnett et al. 1972; Lehman and Ahuja 1985; Flögel and Smith 1999). Hangen et al. (2001) and Doležl et al. (2004) found interflow to be a major component in stream flow with contributions of up to $50 \%$ to the water in a stream. In addition, investigators have used field studies to measure and describe the interflow mechanism responsible for carrying chemical compounds into lotic systems. 
In particular, herbicide (Baker 1985; Periera et al. 1990; Goolsby et al. 1997; Nga and Clegg 1997) and nutrient (Thome et al. 1993; Miller et al. 2005; Marcé and Armengol 2009; Tao et al. 2012) episodic runoff is directly tied to an interflow pathway occurring in highly intensive agricultural areas. As storm water percolates through soil particles, fertilizer and pesticide compounds are cohesively bonded to water molecules and infiltrate soil profiles to enter an interflow runoff pathway. Chemical losses relative to landscape application can vary immensely from one runoff event to another, with the highest levels occurring immediately post - intensive rainfall. Yet, even with current knowledge of input pathways and chemical plume dispersion, little is known about the time - series exposure parameters as they relate to chemical plumes from nonpoint sources entering from subsurface runoff and the hydrodynamics of a fluvial system. Additionally, there are very few studies in the current literature that attempt to address chemical pollutant fate in smaller fluvial systems (Ashauer et al. 2006).

This study examined the relationship between interflow runoff and hydrodynamics of a fluvial system by characterizing in situ tracer plume properties. The focus was to characterize time - series exposure profiles available to organisms of fluvial habitats. We chose to examine fine - scale spatial and temporal plume characteristics using dopamine in two physically different first order streams of Northern Michigan. We predicted the physics of the habitat will result in differential exposure profiles with an intermittent and fluctuating concentration with varying degrees of frequency, intensity, and duration. 


\section{METHODS}

Study sites

A flat 100 m section of Carp Creek (Little Carp Lake River) (N45 32’55.96 W84 $\left.4^{\circ} 40^{\prime} 57.52\right)$ and Carp Lake River (N45 ${ }^{\circ} 40^{\prime} 48.78$ W84 $\left.48^{\circ} 50.58\right)$ in Emmet County, Michigan (Fig 1) were selected to examine the relationship between hydrodynamics and interflow chemical plume characteristics. These sections are composed of microhabitats with turbulent characteristics that influence benthic organisms as they forage for food, shelter, or mates (Westerberg 1991; Moore and Grills 1999; Wolf et al. 2009). Carp Creek has a fine sand substrate whereas Carp Lake River is composed of cobble ranging $0.09-0.20 \mathrm{~m}^{2}$ in size. Both sites have consistent ground water input throughout the entire course of each river. To help prevent the alteration of the turbulent structure of each river, streambed slope was consistent throughout the chosen sections and little to no debris was present.

\section{Chemical tracer delivery protocol}

In order to imitate a potential pollution plume influx post a heavy rainfall, we mimicked a single bank interflow pathway of dopamine (Fig 2). At each site, five $0.6 \mathrm{~cm}$ (inner diameter) vinyl Tygon tubes were randomly buried $2.5 \mathrm{~cm}$ below the substrate in a $1.0 \mathrm{~m}^{2}$ area and $1.0 \mathrm{~m}$ from the bank of the river. Tubing was attached to a peristaltic pump (Manostat Cassette, No. 72 500 000) with a connected reservoir containing 6.52 mM dopamine at Carp Creek and $19.61 \mathrm{mM}$ dopamine at Carp Lake River as a tracer element. Given the turbulent structure of Carp Lake River, the greater dopamine concentration ensured detection by the microelectrode (see chemical tracer measurements). At both sites, dopamine was mixed with $0.1 \mathrm{M}$ fluorescein for visual reference. The pump and reservoir remained stationary on the bank during data collection. Delivery of the electrochemical tracer began $15 \mathrm{~s}$ before data collection to allow dye and 
dopamine to reach downstream sampling sites. Tracer elements were released from each Tygon tube at a rate of $50 \pm 8.0 \mathrm{~mL} / \mathrm{min}$. for a total release rate of $210-290 \mathrm{~mL} / \mathrm{min}$ during the entire sampling period at each research site.

\section{Sampling protocol}

To examine hydrodynamic influence on the dispersion of chemical plumes from interflow groundwater, we measured stream velocity in three different axes (upstream downstream, cross - channel and vertical) simultaneously with in situ chemical plume characteristics at the same temporal and spatial scales. Sampling locations were chosen to spatially evaluate how organisms are exposed to chemical fluctuations. Within each research site, sampling locations were aligned down the established plume centerline at $0.50,1.0$ and $1.5 \mathrm{~m}$ downstream of the defined input area. At each research site, sampling was conducted at three heights above the substrate of each location, comprising 18 total samples. Sampling was conducted at heights of 2, 4 and $6 \mathrm{~cm}$ above the substrate (Fig 2) to represent common habitat areas for benthic organisms. Sampling was conducted at each height before instruments were moved to the next sampling location.

\section{Turbulence measurements}

An Acoustic Doppler Velocimeter (ADV) (Nortek, AS, Rud, Norway) was used to capture a three dimensional velocity profile at each sampling site. An ADV consists of an acoustic sensor with one transmit transducer and three receive transducers. The three receive transducers are mounted around the transmit transducer at $120^{\circ}$ azimuth intervals. As acoustic beams are transmitted, the receive beams intercept the transmit beam. Interception of the three 
receive beams with the transmit transducer, in combination of the transmit pulse, define the sampling volume. Understanding the operation of the ADV was important in order to establish a height above the substrate. To set a sampling height, the ADV probe continually scanned the region in front of the probe tip for a solid or boundary surface while simultaneously measuring the distance from the sampling volume. The ADV probe, attached to a camera tripod, remained stationary during sampling with legs of the tripod positioned and fixed in a manner to prevent any interference with the upstream flow. An adjustable tripod center column allowed the probe to be set at different heights. A sampling rate of $25 \mathrm{~Hz}$ was used to have a spectrum range sensitive enough to calculate Kolmogorov energy dissipation properties of both research sites. Velocity characteristics were also measured to calculate roughness Reynolds (Re), Kolmogorov (1) and Batchelor microscale ( $\left.\prod_{\mathrm{s}}\right)$ values for each respective research site (see flow data analysis).

\section{Chemical tracer measurements}

Dopamine was measured with a carbon fiber, graphite - epoxy style microelectrode (in house) coupled with an Epsilon electrochemical detection system (Epsilon, Bioanalytical Systems Inc., West Lafyette, IN). The microelectrode was constructed with three $30 \mu \mathrm{m}$ carbon fibers at the tip and attached at the same level of the ADV sampling volume for simultaneous electrochemical data collection. At both research sites, DC Potential Amperometry was used with an initial voltage set to $500 \mathrm{mV}$ and a $100 \mathrm{~Hz}$ noise filter. During sampling, the electrode was set to sample at a rate of $20 \mathrm{~Hz}$ to provide a frequency range and chemical spectrum common to benthic organism sensory systems (Moore et al. 1989; Kozlowski et al. 2003; Wolf et al. 2009). Calibration of the microelectrode was conducted with a series of known dopamine 
concentrations $(25-250 \mu \mathrm{M})$ made with water from each respective research site to obtain a highly linear relationship with measured electrical output. The regression allowed conversion of electrical current recorded by the Epsilon system to micromolar dopamine concentrations measured in each chemical spectrum of each sampling point, where $\mathrm{Y}=$ current recorded and $\mathrm{X}$ $=$ concentration. After calibration, we standardized concentrations for comparison between sites by dividing the converted micromolar concentrations of collected time - series data by the original source concentration.

\section{Data Analysis}

Flow data

Velocity depth profiles collected from the ADV were analyzed with Explore V (Nortek AS, Rud Norway) to obtain velocity averages and power spectrum densities. Three dimensional (upstream - downstream, cross - stream and vertical) time - series data collected for each height and distance downstream were used to calculate density spectrums to break down the chaotic turbulence to observe energy distribution across different frequency ranges (Wolf et al. 2009). An autocorrelation function was constructed utilizing a Fourier Transformation to break down the complex density spectrum into pure sine waves with different frequencies and amplitudes (Moore and Atema 1991) to see the underlying fluctuations within the spectrum. Through spectral analysis we incorporated calculation of Kolmogorov, rough Reynolds and Batchelor microscale values as described in Sanford (1997). For all three microscales, the frictional velocity $\left(\mathrm{U}^{*}\right)$ over the sand and cobble substrate was determined through a log - linear regression of velocity profiles with height against measured flow speed (Moore et al. 1994; Hart 1996; Wolf et al. 2009). The slope from the linear portion of each plot was then used to calculate $U^{*}$ as: 


$$
U^{*}=\sqrt{\frac{\tau_{\omega}}{\rho}}
$$

where $\tau_{\omega}$ is the shear stress observed from the regression at the benthic sublayer and $\rho$ is Carp Creek or Carp Lake River water density (Moore and Crimaldi 2004; Wolf et al. 2009). To have an aggregate measure of turbulence at Carp Creek and Carp Lake River we calculated the roughness Reynolds number as a ratio of inertial and viscous forces:

$$
R e^{*}=\frac{U^{*} D}{v}
$$

Substrate type is equal to $\mathrm{D}$ and $v$ is equal to the kinematic viscosity $\left(0.01 \mathrm{~cm}^{2} / \mathrm{s}\right)$ of Carp Creek and Carp Lake River. The rate of energy dissipation $(\varepsilon)$ was then calculated as:

$$
\varepsilon=\left(U^{*}\right)^{3}\left(\kappa^{-1}\right)\left(z^{-1}\right)
$$

where $\mathrm{k}$ is von Karman's constant (0.41) and $\mathrm{z}$ represents height above the substrate. Energy dissipation ( $(\varepsilon)$ was used to calculate both Kolmogorov and Batchelor microscales of Carp Creek and Carp Lake River. The Kolmogorov microscale (П):

$$
\eta=2 \pi\left(\frac{v^{3}}{\varepsilon}\right)^{\frac{1}{4}}
$$

gives a value at which fluid inertia is no longer important in turbulent flow, as a measurement of the smallest eddy structure present (Sanford 1997; Moore and Crimaldi 2004; Wolf et al. 2009). Similarly, the Batchelor microscale:

$$
\eta_{s}=2 \pi\left(\frac{v D_{s}^{2}}{\varepsilon}\right)^{\frac{1}{4}}=\eta\left(\frac{v}{D_{S}}\right)^{\frac{-1}{2}}
$$

incorporates molecular diffusivity to describe the smallest chemical structures present (Moore and Crimaldi 2004; Wolf et al. 2009). The Batchelor microscale (Пs) provides a measurement of 
the smallest distance required to have a chemical concentration ('patch' structure) change at each location (Wolf et al. 2009), where $D_{S}$ is the molecular diffusivity of dopamine $\left(2 \times 10^{-5} \mathrm{~cm}^{2} / \mathrm{s}\right)$.

Chemical plume data

Since an average concentration value is often a poor indicator of chemical plume characteristics due to neglecting the fluctuating plume structure and real - time exposure available for organisms (Elkinton and Cardé1984), electrochemical data were evaluated through a time - series analysis. Evaluation of fine - scale temporal chemical plume characteristics is imperative to understand how organisms are exposed at a high resolution for greater biological and ecological significance (Wolf et al. 2009). Organisms are equipped with sensors to experience and be exposed to chemical plume characteristics most prevalent to their life history (Vickers et al. 2001).

To observe chemical plume parameters most relevant to exposure by an organism (Moore and Atema 1988; 1991; Moore and Grills 1999, Wolf et al. 2009) within each time - series, temporal aspects of chemical spectrums were characterized and broken down into chemical pulses (bursts) with an in house program. Chemical peaks (pulses) within each fluctuating time series chemical spectrum were recognized when concentration values above a designated threshold fell below $40 \%$ of the previous pulse and rose again. Intermittency (off - time between pulses), peak height (maximum concentration), peak length (duration of peak concentration) and slope (maximum) of each pulse were calculated. Intermittency provides a relative measure of how organisms are repetitively exposed to concentrations that highly influence the nervous system (Moore et al. 1989, Moore and Grills 1999, Wolf et al. 2009). Peak height provides a maximum exposure concentration at any instantaneous moment in time, while maximum slope 
of each peak empirically provides insight to how quickly an organism can be subjected to changes in chemical concentration. Furthermore, a peak to mean ratio was calculated by dividing each chemical pulse identified by the in - house program in the chemical spectrum by the mean concentration of that chemical spectrum. Differences in maximum peak height, peak slope, peak to mean ratio, peak length, and intermittency in our study stream sections, with interaction of location, sampling height and distance from the input area were evaluated using a three - way factorial MANOVA with a Fisher LSD post - hoc. A linear discriminant analysis was conducted to observe grouping and further explain chemical plume differences between Carp Creek and Carp Lake River. 


\section{RESULTS}

Hydrodynamics

Velocity profiles

Mean three dimensional (stream - wise, cross - stream and vertical) velocity profiles showed contrasting flow patterns at Carp Creek and Carp Lake River. Differences in the three dimensional flow fields were observed in power spectra of both sites (Fig 3). Time - series analysis revealed Carp Lake River exhibited higher spectral density fluctuation than Carp Creek at all heights above the substrate. This difference in the spectral density function increased as height above the substrate increased (Fig 3). In addition, Carp Lake River exhibited a greater energy dissipation rate $(\varepsilon)$ (Table 1). Calculated Kolmogorov $(\Pi)$ and Batchelor microscales were larger at Carp Creek than at Carp Lake River. Frictional velocity $(* U)$ was greater at Carp Lake River than Carp Creek (0.199 and $0.242 \mathrm{~cm} / \mathrm{s}$, respectively) and calculated roughness Reynolds (*Re) was greater at Carp Lake River than Carp Creek (Table 2).

Fine - scale plume structure

Overall, fine - scale measurements of the dopamine plume microstructure differed significantly between Carp Creek and Carp Lake River (MANOVA, F $32,10398=73.12, \mathrm{p}<$ 0.0001). A linear discriminant analysis showed peak height, max slope, and peak to mean ratio as the three main grouping characteristics (Fig 4).

\section{Peak height}

As a percent dilution to standardize comparisons between each research site, six of the nine sampling locations showed significantly greater peak height at Carp Lake River when compared to Carp Creek (Fisher LSD post - hoc test, $\mathrm{p}<0.001$ ). Five of these significant 
differences were located at sampling points $6 \mathrm{~cm}$ and $4 \mathrm{~cm}$ above the substrate (Fisher LSD post - hoc test, $\mathrm{p}<0.001$ ) (Fig 5). Carp Creek peak height was significantly greater than Carp Lake River at the location nearest the chemical source area, $2 \mathrm{~cm}$ above the substrate (Fisher LSD post - hoc test, $\mathrm{p}<0.001)$. No significant difference was observed at one point farther downstream $(150 \mathrm{~cm})$ nearest the substrate $(2 \mathrm{~cm})(\mathrm{p}>0.05)$.

Slope

Similar to peak height, maximum peak slope was significantly greater at Carp Lake River than Carp Creek at eight of the nine sampling locations (Fisher LSD post - hoc test, $\mathrm{p}<0.001$ ) (Fig 5). Sample points $100 \mathrm{~cm}$ downstream of the source area showed significantly greater slopes at Carp Lake River (mean $638.4 \pm 73.3 \mu \mathrm{M} / \mathrm{s}$ ) than Carp Creek (mean $49.9 \pm 80.8 \mu \mathrm{M} / \mathrm{s}$ ) (Fisher LSD post - hoc, $\mathrm{p}<0.001$ ). The only location which was not greatest at Carp Lake River was farther downstream $(150 \mathrm{~cm})$ of the source area and nearest the substrate.

Peak to mean ratio

As a measure of percent exposure, pulses rising above each spectrum average were significantly greater at Carp Creek (mean 562.6 $\pm 11.0 \%$ ) than Carp Lake River (mean $177.3 \pm$ $9.1 \%$ ) (Fisher LSD post - hoc test, $\mathrm{p}<0.001$ ) (Fig 6). Pulses rising above the average concentration near the source area were significantly greater at Carp Creek $(1040.6 \pm 19.1 \%)$ when compared to Carp Lake River $(162.2 \pm 11.8 \%$ ) (Fisher LSD, p < 0.001). In addition, Carp Creek maintained a significantly greater peak to mean ratio near the substrate at all distances from the input area (Fisher LSD post - hoc, $\mathrm{p}<0.0001$ ). Farther downstream, sample points at 4 
$\mathrm{cm}$ and $6 \mathrm{~cm}$ above the substrate, peak to mean ratio was not significantly different between sites $(\mathrm{p}>0.05)$

Intermittency

Contrary to peak height, intermittency was significantly longer at Carp Creek when compared to Carp Lake River at seven of the nine sampling locations (Fig 6), including all points $4 \mathrm{~cm}$ and $6 \mathrm{~cm}$ above the substrate (Fisher LSD post - hoc test, $\mathrm{p}<0.001$ ). Carp Creek showed longer intermittency at one sampling point $2 \mathrm{~cm}$ above the substrate (Fisher LSD post - hoc test, $\mathrm{p}<0.001)$. In addition, nearest to the chemical source area, Carp Creek intermittency increased significantly as the probe was raised to greater heights above the substrate while Carp Lake River showed no such relationship (Fisher LSD post - hoc test, $\mathrm{p}<0.01$ ).

Peak length

Peak length was significantly longer at Carp Lake River than Carp Creek at four of the nine sampling locations (Fisher LSD post - hoc, $\mathrm{p}<0.003$ ) (Fig 6). Differences in peak lengths were observed farther downstream as Carp Lake River exhibited a significantly longer peak length than Carp Creek near the substrate (Fisher LSD post - hoc, $\mathrm{p}<0.001$ ). In addition, at a sampling distance of $100 \mathrm{~cm}$, peak length at Carp Lake River (mean $0.889 \pm 0.028 \mathrm{~s}$ ) was significantly longer at all heights than Carp Creek (mean $0.432 \pm 0.031 \mathrm{~s}$ ) (Fisher LSD post hoc, $\mathrm{p}<0.001)$. Near the chemical source, peak length was not significantly different between sites $(p>0.05)$.

Time above average 
The amount of time spent above the average concentration was overall highest at Carp Lake River (Fig 5). Calculated as a percentage, time spent above the average within Carp Lake River ranged from 38 - $43 \%$, potentially indicative of long and low to moderate exposure. Conversely, the percent of time spent above the average at Carp Creek varied considerably from $13.8 \%$ near the source area to $25.2-41.7 \%$ farther downstream, potentially indicative of shorter, yet extremely intense exposure periods when compared to Carp Lake River. 


\section{DISCUSSION}

This study examined the relationship between interflow runoff and hydrodynamics of a fluvial system by characterizing tracer plume properties. Fine - scale characteristics of the spatio - temporal microstructure of the dopamine tracer plume were significantly different between Carp Creek and Carp Lake River, two fluvial systems with fundamentally different microhabitats. Differences in plume characteristics were evidenced by greater peak height, longer peak length and greater slopes of those peaks at Carp Lake River than at Carp Creek. Conversely, intermittency and peak to mean ratios were consistently greater over the sand substrate of Carp Creek than over the more complex gravel and cobble substrate at Carp Lake River. Differences in chemical plume characteristics were most likely due to differences in the physical hydrodynamics of the habitat (Webster and Weissburg 2009; Wolf et al. 2009). Flow field characterization (spectral density, ${ }^{*} \mathrm{U}, \varepsilon$ and ${ }^{*} \mathrm{Re}$ ) showed a greater degree of turbulence at Carp Lake River than at Carp Creek. Furthermore, larger Kolmogorov (eddy size) and Batchelor microscales (distance for chemical change) were calculated at Carp Creek. Taken together, these flow and plume characteristics indicate less mixing and more bulk advection at Carp Creek while higher levels of turbulent advection and mixing were observed at Carp Lake River. This would explain the increased background average (denoted by the lesser peak to mean ratio) of Carp Lake River. Furthermore, this interdependent linkage between chemical plumes and hydrodynamics has increased our understanding of the fine - scale transmission of chemicals in aquatic habitats.

\section{Chemical plumes and hydrodynamics}

Research on animal orientation behavior in organisms has elucidated the linkage between hydrodynamics and chemical plume structure (Dodds 1990; Moore et al. 1991; Weissburg and 
Zimmer - Faust 1994; Zimmer - Faust et al. 1995; Finelli et al. 1999; 2000; Moore and Grills 1999; Crimaldi et al. 2002; Weissburg et al. 2002; Kozlowski et al. 2003; Weissburg and Webster 2009; Weissburg 2011). As a result of the interdependent linkage between chemical plumes and hydrodynamics, we have dramatically shifted our approach to understanding fine scale chemical transmission in aquatic habitats (Moore et al. 1991; Finelli 2000; Moore and Crimaldi 2004). Chemical dispersion was initially described using statistical Gaussian principles as a homogenous mixture of a chemical within a plume that organisms can use for orientation (Elkinton and Cardé 1984; Elkinton et al. 1984; Wright 1958; Bossert and Wilson 1962). These dispersion models came with a large caveat of assuming neutral atmospheric stability for a normally distributed gradient of chemical for organismic exposure downwind. In addition, Gaussian models only predicted time averaged downwind concentrations based on diffusion coefficients (Elkinton and Cardé 1984). These concentrations were found to be grossly underestimated by a time - averaged model (Wright 1958; Shorey 1976; Elkinton and Cardé 1984).

Similarly in unidirectional fluvial habitats, chemical plume characteristics are not accurately predicted by a Gaussian based model. Exposure defined through Gaussian principles is underestimated when incorporating the relevant spatial and temporal scales at which behavior and physiology operate (Bossert and Wilson 1963; Murlis and Jones 1981; Moore and Atema 1988; Moore et al. 1989; Finelli et al. 2000; Moore and Crimaldi 2004). Any resident organism will likely be exposed to an intermittent chemical plume with widely varying degrees of intensity over temporal periods (Moore and Atema 1981; Finelli 2000; Webster and Weissburg 2009; Weissburg 2011). Turbulent structures (i.e. - eddy currents) stir and mix a chemical plume. Any turbulent structure larger than a patch of chemical will simply move (stir) the patch downstream. 
Conversely, any turbulent structures at or smaller in size to a chemical patch will intersperse chemical filaments with non - chemical containing water filaments (Weissburg 2011). With nonpoint source pollutant entry commonly occurring over a stretch of riparian area, these general hydrodynamic and subsequent plume structure concepts can be widely applicable at different spatial scales (i.e.- stretch of stream). Results of this study exemplify a greater turbulent environment produces an exposure situation that is highly fluctuating and chaotic in frequency, duration, and intensity. Moreover the time and distance traveled downstream to chemical dilution below some physiological threshold may be reduced in highly turbulent systems because of increased mixing. This concept of a heterogeneous composition of turbulent chemical plumes has been lacking a relevant connection to a large amount of the environmental ecotoxicology research and definitions of exposure that need to be incorporated for adequate linkage of laboratory studies to natural habitats.

\section{A new concept of exposure}

How exposure is defined will dictate the scale of interest and perception of ecotoxicity in aquatic organisms. Currently, the U. S. Environmental Protection Agency (EPA) utilizes a deterministic and probabilistic approach when sources of anthropogenic pollutants are involved. A deterministic approach compares static toxic effect levels (e.g. LC50) with an estimated environmental concentration (EEC). A probabilistic approach provides a distribution or range of concentration values to predict the deleterious intensity of a particular pollutant (USEPA 2004; 2007). Yet, as previously stated, deleterious exposure can be defined as interacting terms of intensity, frequency and duration (Gordon et al. 2012). 
Recent literature has attempted to incorporate these interacting terms through the usage of pulsed exposures in order to mimic an episodic influx, coupled with subsequent recovery time (Milne et al. 2000; Reinert et al. 2002; Diamond et al. 2005; 2006; Zhao and Newman 2006; Sandahl et al. 2006; Chen et al. 2012). These studies have focused on specific sub - lethal exposure of an organism to a toxin at various time - averaged, static concentrations with some behavioral or physiological end point measurement(s) (Diamond et al. 2005; 2006; Earl 2009; Wang 2011). However, nonpoint source runoff is more often temporally episodic in nature, resulting in concentrations that already fluctuate in frequency, intensity and duration with variable toxic effects (Diamond et al. 2005; Gordon et al. 2012) even without the aforementioned hydrodynamic influence on a chemical plume. Given this, we have a great opportunity in place to parse out exposure to pollutants from nonpoint sources from a mechanistic perspective by considering the spatio - temporal gradient within an ecosystem (Clements et al. 2012).

\section{Time - series exposure}

In any field fluvial system, concepts of total exposure need to incorporate some intensity (i.e. peak height, peak to mean ratio), time (i.e. slope, peak length, time above average) and an interaction of intensity and time (frequency). Each habitat sampled in this study had hydrodynamic traits that created unique plume characteristics. Time and intensity parameters were shown to vary independently at Carp Lake River and Carp Creek habitats. Taken as such, exposure defined under older Gaussian and static concepts reveal a different picture than a more ecologically relevant concept of exposure that incorporates intensity and time parameters at these finer scales. For example, a measure of exposure or habitat pollution defined only by a Gaussian model of intensity would indicate that Carp Lake River had higher concentrations of dopamine. 
Yet, a more relevant model that included peak height comingled with peak length would determine that both pollution plumes modeled here had roughly equivalent exposure danger for their respective habitats. Furthermore, a different intensity characteristic, such as peak to mean ratio, comingled with peak length may reveal a significantly more intense exposure scenario at Carp Creek than at Carp Lake River.

Time average models are poor predictors of animal behavior and, by extension, poor predictors of physiological responses. Within natural systems (and demonstrated by the data here), intense fluctuations in concentrations of toxins are the most common form of natural exposure. Simple changes in the intermittency of an exposure paradigm have shown to significantly alter the survival of amphipods (Ashauer et al. 2006). Given our findings, this means that given the same source concentration of toxin, release of toxins in Carp Creek would have a greater impact on the aquatic ecosystem than an identical exposure in Carp River. Similar findings have been found for fish and invertebrates (Handy 1994). Thus, measurements of peak height and intermittency are essential to connect these laboratory studies with natural exposure.

Within the concept of exposure, organisms will likely have different tolerance levels with the interaction of time, intensity and frequency (Diamond et al. 2005; Hoang et al. 2007; Earl and Whiteman 2009; Wang 2011). One organism may be more tolerant to certain chemical 'patches' (concentrations in space) but not in a temporal fashion and vice versa. Meaning, an organism may be more, or less tolerant to short, extremely intense chemical bursts (relative to the mean) when experiencing a 'patch' of chemical as seen at Carp Creek. Conversely, an organism may be more or less tolerant to long, low intense exposures (relative to the mean) as we observed at Carp Lake River. Research has shown intensity to be the major determinant of toxicity as concentrations exceed some tissue burden threshold (Pynnonen 1990; Gordon et al. 
2012). Repetitive pulsed exposure has also been shown to have widely variable effects with exposure time (Diamond et al. 2006; Gama - Flores et al. 2006; Bearr et al. 2006; Hoang and Klaine 2008). Morphological differences such as gill surface area (Peterson et al. 2001), chemical ability of binding to epithelial tissues (Mirza et al. 2008), metabolic and excretion rates have also been suggested for response differences between organisms in pulsed exposure studies. The symptomology of deleterious effects for exposures modeled within this study are difficult to interpret as organismal impact is widely variable and difficult to predict.

Just as physiological systems (sensory) have evolved to be efficient in microhabitats (Endler 2000; Vickers 2001) selective pressures can arise if these same systems become impaired from fluctuating exposures. Due to this complex relationship between fluid dynamics, pollution exposure, and organism physiology the argument for use of flow - through systems in the lab has increased and is preferred over static exposure paradigms (Welsh et al. 2008).

Flow - through systems, although less cost - effective than static exposure tests, provide greater control of pollutant concentrations and natural applicability to fluvial habitat conditions than static exposure tests. Static tests have been found to underestimate toxicity of Copper in rainbow trout when compared to flow through systems (Welsh et al. 2008). 'Furthermore, when ecotoxicology data are available from static and flow - through tests for the same chemical pollutant, results of the static test are typically discounted (Welsh et al. 2008; Stephan 1985). In addition to flow - through systems, focus to overcome episodic challenges has shifted in recent years to incorporate greater temporal resolution as described in this study (Gordon et al. 2012). Microfluidic field technology and autonomous instruments are progressing with measurements that use small volumes of water with increased sampling frequency. These instruments are 
increasing in demand to provide reliable data, already in use monitoring effluent wastewater (Glasgow et al. 2004; Cleary et al. 2013).

Microfluidic technology is at the forefront of adapting the idea for real - time exposure presented within this field study. Microfluidic sensory systems are showing promise as they have the capacity for greater measuring frequency of eutrophic constituents (i.e. phosphate, nitrate, $\mathrm{pH}$, etc.) for in situ systems. The minute, hourly, and daily measurement frequency allows capture of smaller scale temporal variations important for organismic exposure that provides more information than static sample - based (time - averaged) measurements (Glasgow et al. 2004; Korostynska et al. 2013; Cleary et al. 2013). Yet, data presented in this field study show there is still potential to move further down in scale. We have the capacity to evaluate instantaneous exposure within an episodic runoff event to real - time exposure that, from a sensory standpoint, is more biologically relevant. Future development of real - time, autonomous instruments should be eventually integrated with other physio - chemical sensors for hydrodynamic influences and pesticides, or breakdown products thereof. Furthermore, lab incorporation of microfluidic sensor technology in conjunction of flow - through systems will greatly ameliorate the field application of ecotoxicity laboratory studies.

\section{Conclusions}

Ecotoxicity from exposure is organism and chemical dependent, but is also a measure of plume dispersion. In order to improve exposure predictions, measurements and subsequent water quality impairment criteria within natural aquatic habitats, the spatio - temporal gradient within environments needs to be examined. This field study demonstrated the ability to collect fine scale dispersal data of an in situ chemical plume through mimicked interflow runoff. Through 
fine - scale measurements, we can move forward to gain important knowledge of pollution plume movement through aquatic systems that contain a hydrologic link to the surrounding landscape. Future studies will be able to incorporate exposure and specific ecotoxicity parameters with an understanding of plume distribution for greater biological relevance. Subsequently, fine - scale intensity and time parameters will enhance water impairment criteria to better represent deleterious exposure to a variety of organisms. The relationships between fluid dynamics of fluvial systems, pollution exposure and organism physiology are complex, context dependent and need to be evaluated, if not in the field, through mimicking natural habitats in flow - through systems. 


\section{REFERENCES}

Ashauer R, Boxall A, Brown C (2006) Predicting effects on aquatic organisms from fluctuating or pulsed exposure to pesticides. Environ Toxicol Chem 25:1899-912.

Baker DB (1985) Regional water quality impacts of intensive row - crop agriculture: a Lake Erie basin case study. Soil Water Conserv 40:125-132.

Barnett AP, Carrekar JR, Abruna F, et al. (1972) Soil and nutrient losses in runoff with selected cropping treatments on tropical soils. J Agron 64:391-305.

Bearr JS, Diamond J, Latimer H, Bowersox M (2006) Effects of pulsed copper exposures on early life - stage Pimephales promelas. Environ Toxicol Chem 25:1376-82.

Bossert WH, Wilson EO (1962) The analysis of olfactory communication among animals. J Theor Biol 5:443-469

Buffin - Bélanger T, Rice S, Reid I, Lancaster J (2006) Spatial heterogeneity of near - bed hydraulics above a patch of river gravel. Water Resour Res. doi: 10.1029/2005WR004070

Butcher J, Diamond J, Bearr J, et al. (2006) Toxicity models of pulsed copper exposure to Pimephales promelas and Daphnia magna. Environ Toxicol Chem 25:2541-50.

Chen W - Y, Lin C - J, Ju Y - R, et al. (2012) Assessing the effects of pulsed waterborne copper toxicity on life-stage tilapia populations. Sci Total Environ 417 - 418:129-37. doi: 10.1016/j.scitotenv.2011.12.043

Cleary J, Maher D, Diamond D (2013) Smart sensors for real - time water quality monitoring. 125-148. doi: 10.1007/978-3-642-37006-9

Clements WH, Hickey CW, Kidd KA (2012) How do aquatic communities respond to contaminants? It depends on the ecological context. Environ Toxicol Chem 31:1932-40. doi: 10.1002/etc. 1937 
Crimaldi JP, Oehl MAR, Koseff JR (2002) Effects of the resolution and kinematics of olfactory appendages on the interception of chemical signals in a turbulent odor plume. Environ Fluid Mech 2:35-63.

Denny MW (1993) Air and water: the biology and physics of life's media. Princeton University Press, New Jersey.

Diamond J, Bowersox M, Latimer H, et al. (2005) Effects of pulsed contaminant exposures on early life stages of the fathead minnow. Arch Environ Contam Toxicol 49:511-9. doi: $10.1007 / \mathrm{s} 00244-005-7023-8$

Diamond JM, Klaine SJ, Butcher JB (2006) Implications of pulsed chemical exposures for aquatic life criteria and wastewater permit limits. Environ Sci Technol 40:5132-8.

Dodds WK (1990) Hydrodynamic constraints on evolution of chemically mediated interactions between aquatic organisms in unidirectional flows. J Chem Ecol 16:1417-1430. doi: 10.1007/BF01021037

Doležal F, Kv tek T (2004) The role of recharge zones, discharge zones, springs and tile drainage systems in peneplains of Central European highlands with regard to water quality generation processes. Phys Chem Earth 29:775-785. doi: 10.1016/j.pce.2004.05.005

Earl JE, Whiteman HH (2009) Effects of pulsed nitrate exposure on amphibian development. Environ Toxicol Chem 28:1331-7. doi: 10.1897/08-325.1

Endler J (2000) Evolutionary implicaions of the interaction between animal signals and the environment. In: Amundsen T, Rosenqvist G (eds) Anim. Signals Signal. signal Des. Anim. Commun. Tapir Academic Press, Trondheim, Norway, pp 11-46.

Elkinton, JS and Cardé, RT (1984) Odor dispersion. In: W.J. Bell and R.T. Cardé (eds) Chemical Ecology of Insects, Sunderland, MA: Sinauer Associates, pp. 73-92. 
Elkinton JS, Cardé RT, Mason CJ (1984) Evaluation of time - averaged dispersion models for estimating pheromone concentration in a deciduous forest. J Chem Ecol 10:1081-108.

Finelli CM (2000) Velocity and concentration distributions in turbulent odor plumes in the presence of vegetation mimics: a flume study. Mar Ecol Prog Ser 207:297-309. doi: $10.3354 /$ meps 207297

Finelli CM, Pentcheff ND, Zimmer RK, Wethey DS (2000) Physical constraints on ecological processes: a field test of odor - mediated foraging. Ecology 81:784-97.

Finelli CM, Pentcheff ND, Zimmer - Faust RK, Wethey DS (1999) Odor transport in turbulent flows: constraints on animal navigation. Limnol Oceanogr 44:1056-71.

Flügel W - A (1993) Hierarchically structured hydrological process studies to regionalize interflow in a loess covered catchment near Heidelberg, Germany. Exch Process L Surf a Range Sp Time Scales 212:215-223.

Flügel W - A, Smith RE (1999) Integrated process studies and modelling simulations of hillslope hydrology and interflow dynamics using the HILLS model. Environ Model Softw 14:153-160.

Gama - Flores JL, Sarma SSS, Nandini S. (2006) Effect of cadmium level and exposure time on the competition between zooplankton species Moina macrocopa (Clodocera) and Brachionus calyciforus (Rotifera). J Environ Sci Heal A 41:1057-1070.

Glasgow HB, Burkholder JM, Reed RE, et al. (2004) Real - time remote monitoring of water quality: a review of current applications, and advancements in sensor, telemetry, and computing technologies. J Exp Mar Bio Ecol 300:409-48. doi:

10.1016/j.jembe.2004.02.022 
Goolsby DA, Thurman EM, Pomes ML, et al. (1997) Herbicides and their metabolites in rainfall: origin, transport, and deposition patterns across the midwestern and northeastern United States, 1990-1991. Environ Sci Technol 31:1325-33. doi: 10.1021/es960847o

Gordon AK, Mantel SK, Muller NWJ (2012) Review of toxicological effects caused by episodic stressor exposure. Environ Toxicol Chem 31:1169-74. doi: 10.1002/etc.1781

Handy RD (1994). Intermittent exposure to aquatic pollutants: assessment, toxicity and sublethal responses in fish and invertebrates. Comp Biochem Phys C: Pharm, Tox and Endo 107(2): 171 - 184. doi: http://dx.doi.org/10.1016/1367-8280(94)90039-6

Hangen E, Lindenlaub M, Leibundgut C, Wilpert K Von (2001) Investigating mechanisms of stormflow generation by natural tracers and hydrometric data: a small catchment study in the Black Forest, Germany. Hydrol Process 15:183-199.

Hart DD, Clark BD, Jasentuliyana A (1996) Fine - scale field measurement of benthic flow environments inhabited by stream invertebrates. Limnol Oceanogr 41:297-308.

Hoang TC, Gallagher JS, Tomasso JR, Klaine SJ (2007) Toxicity of two pulsed metal exposures to Daphnia magna: relative effects of pulsed duration - concentration and influence of interpulse period. Arch Environ Contam Toxicol 53:579-89. doi: 10.1007/s00244-0060266-1

Hoang TC, Klaine SJ (2008) Characterizing the toxicity of pulsed selenium exposure to Daphnia magna. Chemosphere 71:429 - 438.

Korostynska O, Mason A, Al - shamma AI (2013) Monitoring pollutants in wastewater: traditional lab based versus modern real - time approaches. Monit Pollut Wastewater 124. doi: 10.1007/978-3-642-37006-9 
Kozlowski C, Voigt R, Moore PA (2003) Changes in odour intermittency influence the success and search behaviour during orientation in the crayfish (Orconectes rusticus). Mar Freshw Behav Physiol 36:97-110. doi: 10.1080/1023624031000136279

Lehman OR, Ahuja LR (1985) Interflow of water and tracer chemical on sloping field plots with exposed seepage faces. J Hydrol 76:307-317.

Li H, Sivapalan M (2011) Effect of spatial heterogeneity of runoff generation mechanisms on the scaling behavior of event runoff responses in a natural river basin. Water Resour Res 47:1-20. doi: 10.1029/2010WR009712

Marcé R, Armengol J (2009) Modeling nutrient in - stream processes at the watershed scale using nutrient spiraling metrics. Hydrol Earth Syst Sci 13:501-533. doi: 10.5194/hessd-6501-2009

McGraw CM, Stitzel SE, Cleary J, et al. (2007) Autonomous microfluidic system for phosphate detection. Talanta 71:1180-5. doi: 10.1016/j.talanta.2006.06.011

Miller WW, Johnson DW, Denton C, et al. (2005) Inconspicuous nutrient laden surface runoff from mature forest Sierran watersheds. Water Air Soil Pollut 163:3-17.

Milne I, Seager J, Mallett M (2000) Effects of short - term pulsed ammonia exposure on fish. Environ Toxicol Chem 19:2929-2936.

Mirza RS, Green WW, Connor S, et al. (2009) Do you smell what I smell? Olfactory impairment in wild yellow perch from metal - contaminated waters. Ecotoxicol Environ Saf 72:67783. doi: $10.1016 /$ j.ecoenv.2008.10.001

Moore PA, Atema J (1988) A model of a temporal filter in chemoreception to extract directional information from a turbulent odor plume. Biol Bull 174:355-363. 
Moore PA, Atema J (1991) Spatial information in the three - dimensional fine structure of an aquatic odor plume. Biol Bull 181:408-18.

Moore PA, Crimaldi J (2004) Odor landscapes and animal behavior: tracking odor plumes in different physical worlds. J Mar Syst 49:55-64. doi: 10.1016/j.jmarsys.2003.05.005

Moore PA, Gerhardt GA, Atema J (1989) High resolution spatio - temporal analysis of aquatic chemical signals using microelectrochemical electrodes. Chem Senses 14:829-40. doi: 10.1093/chemse/14.6.829

Moore PA, Grills JL (1999) Chemical orientation to food by the crayfish Orconectes rusticus: influence of hydrodynamics. Anim Behav 58:953-963. doi: 10.1006/anbe.1999.1230

Moore PA, Grills JL, Schneider RWS (2000) Habitat - specific signal structure for olfaction: an example from artificial streams. J Chem Ecol 26:565-584.

Moore PA, Scholz N, Atema J (1991) Chemical orientation of lobsters, Homarus americanus, in turbulent odor plumes. J Chem Ecol 17:1293-1307. doi: 10.1007/BF00983763

Moore PA, Shao K (2000) An electrical circuit model of chemoreceptor cells based on adaptation and disadaptation time constants: implications for temporal filtering. Mater Sci Eng 7:149-60. doi: 10.1016/S09284931(99)00137-X

Moore PA, Weissburg MJ, Parrish JM, et al. (1994) Spatial distribution of odors in simulated benthic boundary layer flows. J Chem Ecol 20:255-79.

Murlis J, Jones CD (1981) Fine - scale structure of odor plumes in relation to insect orientation to distant pheromone and other attractant sources. Physiol Entomol 6:71-86.

Nga HYF, Clegg SB (1997) Atrazine and metolachlor losses in runoff events from an agricultural watershed: the importance of runoff components. Sci Total Environ 193:215228. 
Pereira WE, Rostad CE (1990) Occurrence, distributions, and transport of herbicides and their degradation products in the lower Mississippi River and its tributaries. Environ Sci Technol 24:1400-06.

Pynnonen K (1990) Aluminium accumulation and distribution in the freshwater clams (Unionidae). Comp Biochem Physiol 97C:111-117. doi: http://dx.doi.org/10.1016/07428413(90)90180-H

Reinert KH, Giddings JM, Judd L (2002) Effects analysis of time - varying or repeated exposures in aquatic ecological risk assessment of agrochemicals. Environ Toxicol Chem 21:1977-92.

Roy AG, Buffin - Blanger T, Lamarre H, Kirkbride AD (2004) Size, shape and dynamics of large - scale turbulent flow structures in a gravel - bed river. J Fluid Mech 500:1-27. doi: $10.1017 / \mathrm{S} 0022112003006396$

Sandahl JF, Miyasaka G, Koide N, Ueda H (2006) Olfactory inhibition and recovery in chum salmon (Oncorhynchus keta) following copper exposure. Can J Fish Aquat Sci 63:184047. doi: 10.1139/f06-074

Sanford LP (1997) Turbulent mixing in experimental ecosystem studies. Mar Ecol Prog Ser 161:265-293. doi: 10.3354/meps161265

Shen Y, Diplas P (2008) Application of two - and three - dimensional computational fluid dynamics models to complex ecological stream flows. J Hydrol 348:195-214. doi: 10.1016/j.jhydrol.2007.09.060

Shorey HH (1976) Animal communication by pheromones. Academic Press, New York, NY. Stephan CE, Mount DI, Hansen DJ, Gentile JH, Chapman GA, Brungs WA, 1985. Guidelines for deriving numerical national water quality criteria for the protection of aquatic organisms 
and their uses. US Environmental Protection Agency, EPA 822-R-85-100, NTIS PB85 227049, Duluth, Narragansett, and Corvallis, 98pp.

Tao W, Bo Z, Fuhong K (2012) Reducing interflow nitrogen loss from hillslope cropland in a purple soil hilly region in southwestern China. Nutr Cycl Agroecosystems 93:285-295. doi: $10.1007 / \mathrm{s} 10705-012-9515-\mathrm{z}$

U.S. Environmental Protection Agency (US EPA) (2004) OPP's initiative to revise the ecological assessment process for pesticides. IV. The aquatic level II refined risk assessment model (version 2.0). /www.epa.gov/oppefed1/ecoriskS.

U.S. Environmental Protection Agency (US EPA) (2007) National water quality inventory: Report to Congress; 2002 Reporting cycle. Document No. EPA-841-R-07-001. U.S. Government Printing Office, Washington D.C., U.S.A.

U.S. Environmental Protection Agency (US EPA) (2013) ECOTOX Database Release 4.0. www.epa.gov/ecotox. accessed 13.10.13.

Thome U, Kuhbauch W, Stratmann B (1993) Leaching of Nitrogen from permanent grassland treated with cattle slurry. J Agron Crop Sci 90:84-90.

Vickers NJ, Christensen TA, Baker TC, Hildebrand JG (2001) Odour - plume dynamics influence the brain's olfactory code. Nature 410:466-70.

Vogel S (1994) Life in Moving Fluids: the physical biology of flow. Princeton University Press, New Jersey.

Wang W - X (2011) Incorporating exposure into aquatic toxicological studies: an imperative. Aquat Toxicol 105:9-15. doi: 10.1016/j.aquatox.2011.05.016

Webster DR, Weissburg MJ (2009) The hydrodynamics of chemical cues among aquatic organisms. Annu Rev Fluid Mech 41:73-90. doi: 10.1146/annurev.fluid.010908.165240 
Welsh PG, Lipton J, Mebane CA, Marr JCA (2008) Influence of flow - through and renewal exposures on the toxicity of copper to rainbow trout. Ecotoxicol Environ Saf 69:199-208. doi: 10.1016/j.ecoenv.2007.04.003

Wehner R (1987) "Matched filters" - neural models of the external world. J Comp Physiol $161: 511-31$.

Weissburg MJ (2011) Waterborne chemical communication: stimulus dispersal dynamics and orientation strategies in crustaceans. In: Breithaupt T, Thiel M (eds) Chem. Commun. Crustac. Springer New York, New York, NY, pp 63-84.

Weissburg MJ, Dusenbery DB, Ishida H, et al. (2002) A multidisciplinary study of spatial and temporal scales containing information in turbulent chemical plume tracking. Environ Fluid Mech 2:65-94.

Weissburg MJ, Zimmer - Faust RK (1994) Odor plumes and how blue crabs use them in finding prey. J Exp Biol 197:349-75.

Westerberg H (1991) Properties of aquatic odor trails. Proc. tenth Int. Symp. olfaction Tast. Oslo, Norway, pp 45-65.

Wolf MC, Martin III AL, Simon JL, et al. (2009) Chemosensory signals in stream habitats: implications for ecological interactions. J North Am Benthol Soc 28:560-71. doi: 10.1899/08-108.1

Wolf MC, Voigt R, Moore PA (2004) Spatial arrangement of odor sources modifies the temporal aspects of crayfish search strategies. J Chem Ecol 30:501-517.

Wright RH (1958) The olfactory guidance of flying insects. Can Entomol 90:81-89.

Zhao Y, Newman MC (2006) Effects of exposure duration and recovery time during pulsed exposures. Environ Toxicol Chem 25:1298-1304. 
Zimmer - Faust RK, Finelli CM, Pentcheff ND, Wethey DS (1995) Odor plumes and animal navigation in turbulent water flow: A Field Study. Biol Bull 188:111-116. 
TABLES

\begin{tabular}{|c|c|c|c|c|c|c|}
\hline \multirow{2}{*}{$\begin{array}{c}\text { Height above } \\
\text { substrate }(\mathrm{cm})\end{array}$} & \multicolumn{2}{|c|}{$\varepsilon\left(\mathrm{cm}^{2} / \mathrm{s}^{3}\right)$} & \multicolumn{2}{c|}{$\eta(\mathrm{cm})$} & \multicolumn{2}{c|}{$\eta_{\mathrm{s}}(\mathrm{cm})$} \\
\cline { 2 - 7 } & $\begin{array}{c}\text { Carp } \\
\text { Creek }\end{array}$ & $\begin{array}{c}\text { Carp Lake } \\
\text { River }\end{array}$ & $\begin{array}{c}\text { Carp } \\
\text { Creek }\end{array}$ & $\begin{array}{c}\text { Carp Lake } \\
\text { River }\end{array}$ & $\begin{array}{c}\text { Carp } \\
\text { Creek }\end{array}$ & $\begin{array}{c}\text { Carp Lake } \\
\text { River }\end{array}$ \\
\hline 6 & 7.99 & 164.33 & 0.12 & 0.056 & 0.0053 & 0.0025 \\
\hline 4 & 18.01 & 203.30 & 0.097 & 0.053 & 0.0043 & 0.0024 \\
\hline 2 & 127.23 & 321.02 & 0.059 & 0.047 & 0.0026 & 0.0021 \\
\hline
\end{tabular}

Table 1. Hydrodynamic characterization of cobble and sand substrate of Carp Creek and Carp Lake River, Emmet, County, Michigan, USA. $\varepsilon=$ dissipation rate, $\rceil=$ Kolmogorov microscale, $\eta_{\mathrm{s}}=$ Batchelor microscale

\begin{tabular}{|c|c|c|}
\hline Habitat & ${ }^{*} \mathrm{U}(\mathrm{cm} / \mathrm{s})$ & $\mathrm{Re}^{*}$ \\
\hline Carp Creek & 0.199 & 0.836 \\
\hline Carp Lake River & 0.242 & 255 \\
\hline
\end{tabular}

Table 2. Hydrodynamic characterization of the benthic boundary layer of Carp Creek and Carp Lake River, Emmet County, MI, USA. Shear velocity values $(* U)$ were calculated for a height of $2 \mathrm{~cm}$ above the substrate. Re* $=$ roughness Reynolds number 


\section{FIGURES}

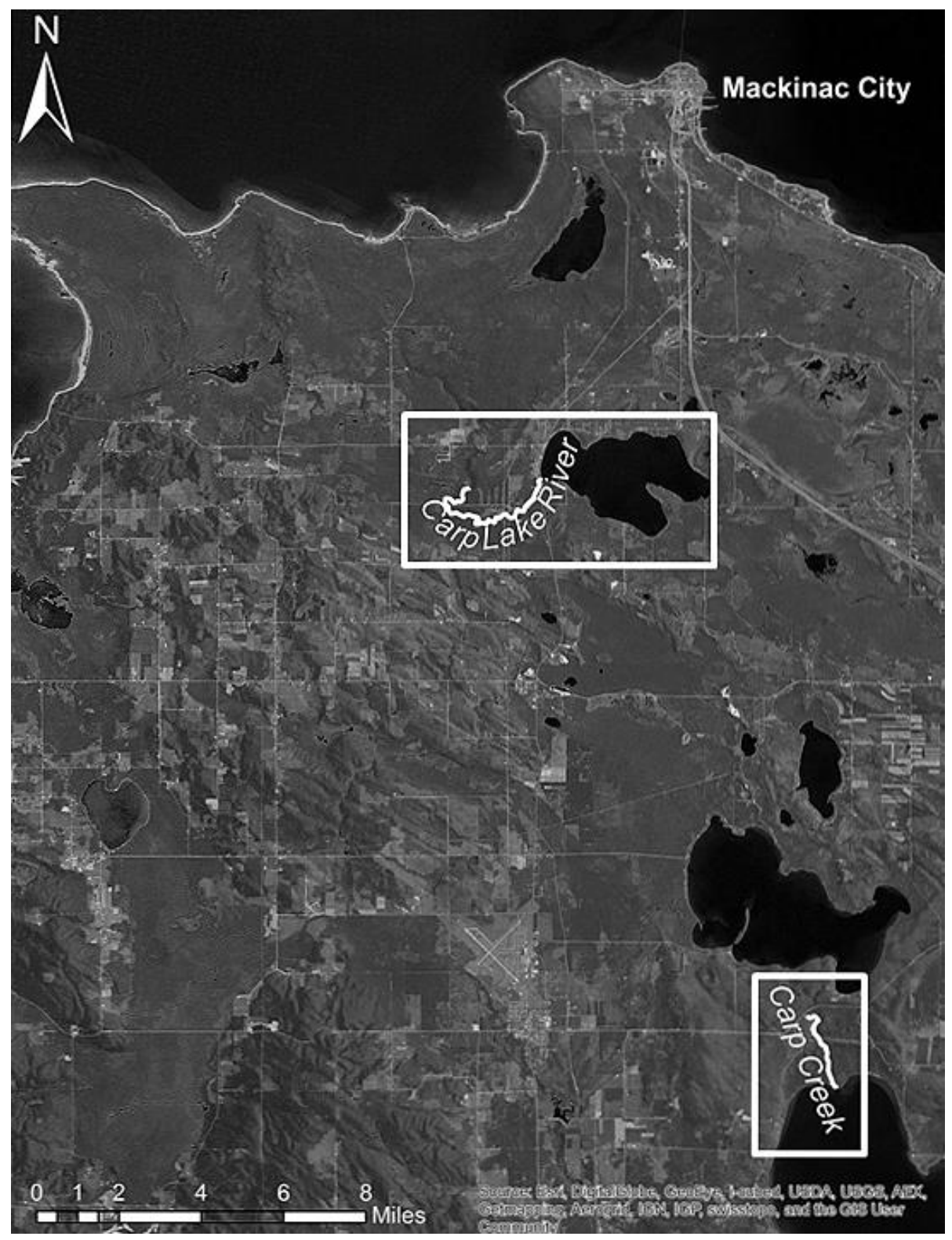

Figure 1. Aerial photograph of Carp Lake River and Carp Creek location within Emmett County, Michigan courtesy of ESRI, ArcGIS Desktop 10.1 and Michigan Geographic Data Library (MiGDL) http://www.mcgi.state.mi.us/mgdl/ 


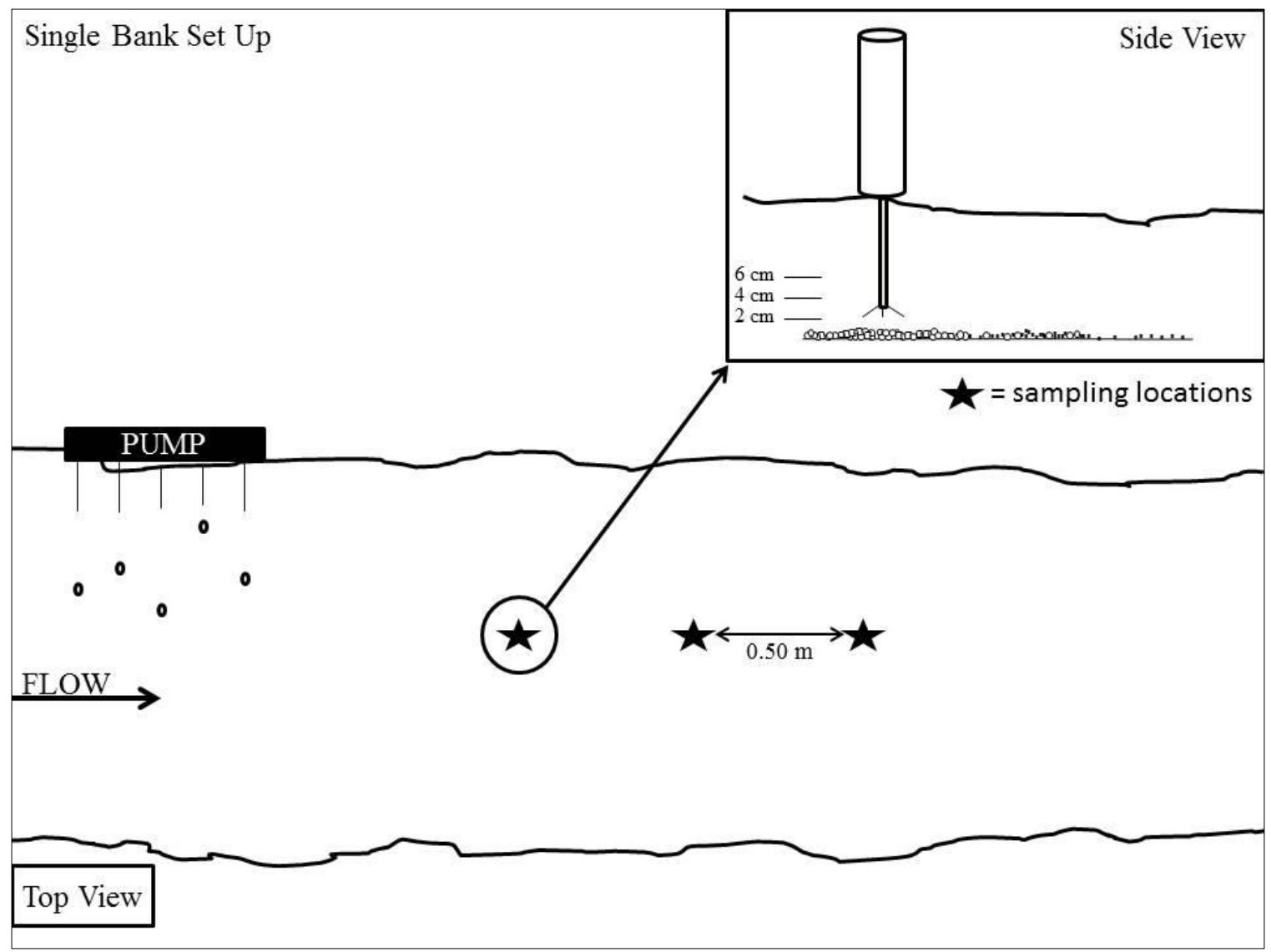

Figure 2. Schematic set - up of field sampling locations at Carp Creek and Carp Lake River. Stars denote sampling locations down the defined plume centerline, not drawn to scale 


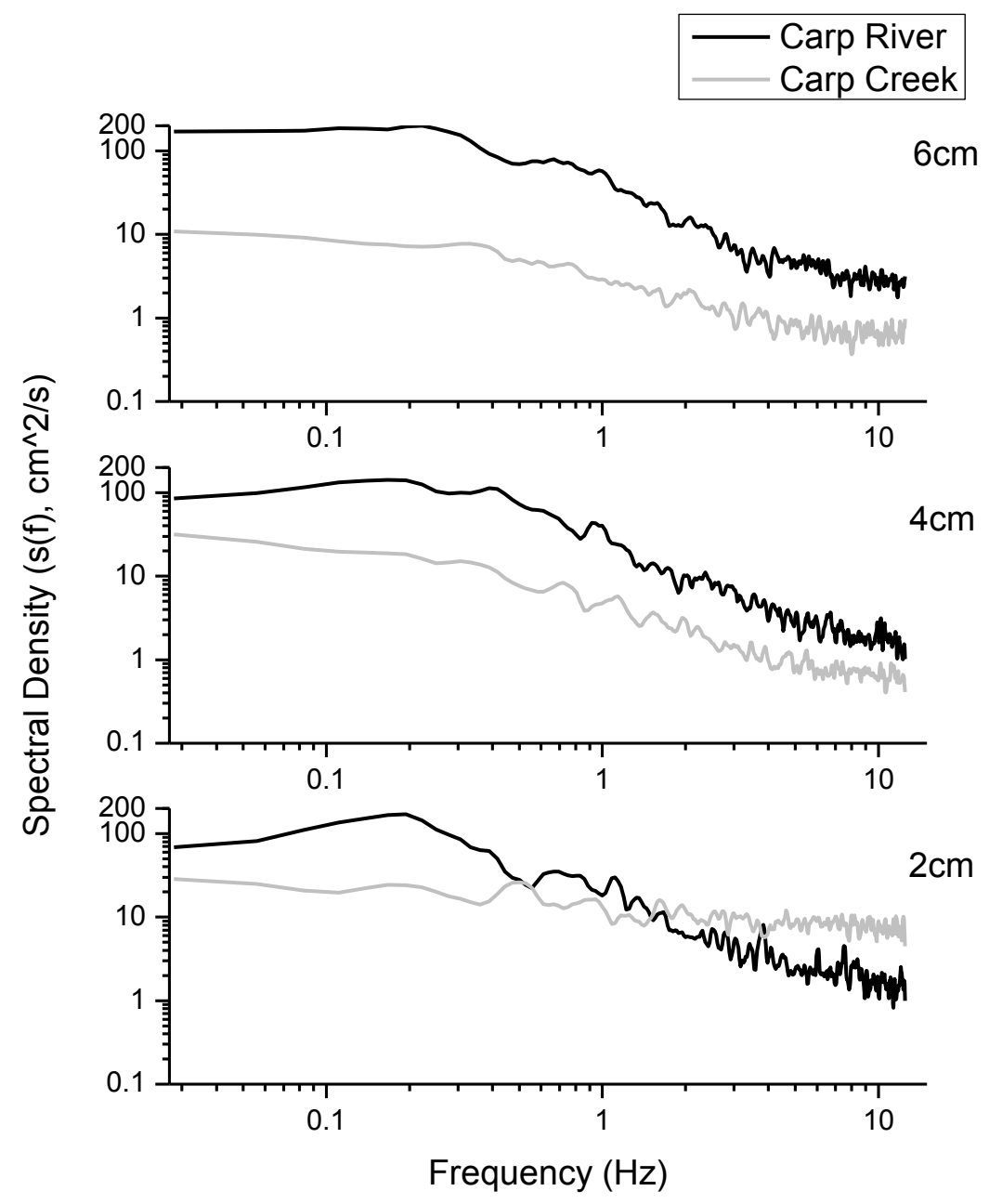

Figure 3. Power Spectral analysis of Time - series flow velocity data at $2 \mathrm{~cm}, 4 \mathrm{~cm}$, and $6 \mathrm{~cm}$ of Carp River (black) and Carp Creek (gray), Emmett Co, MI. Univariate spectral analysis was conducted with a Fourier transformation autocovariance function smoothed with a Tukey weighting and adjacent average technique 


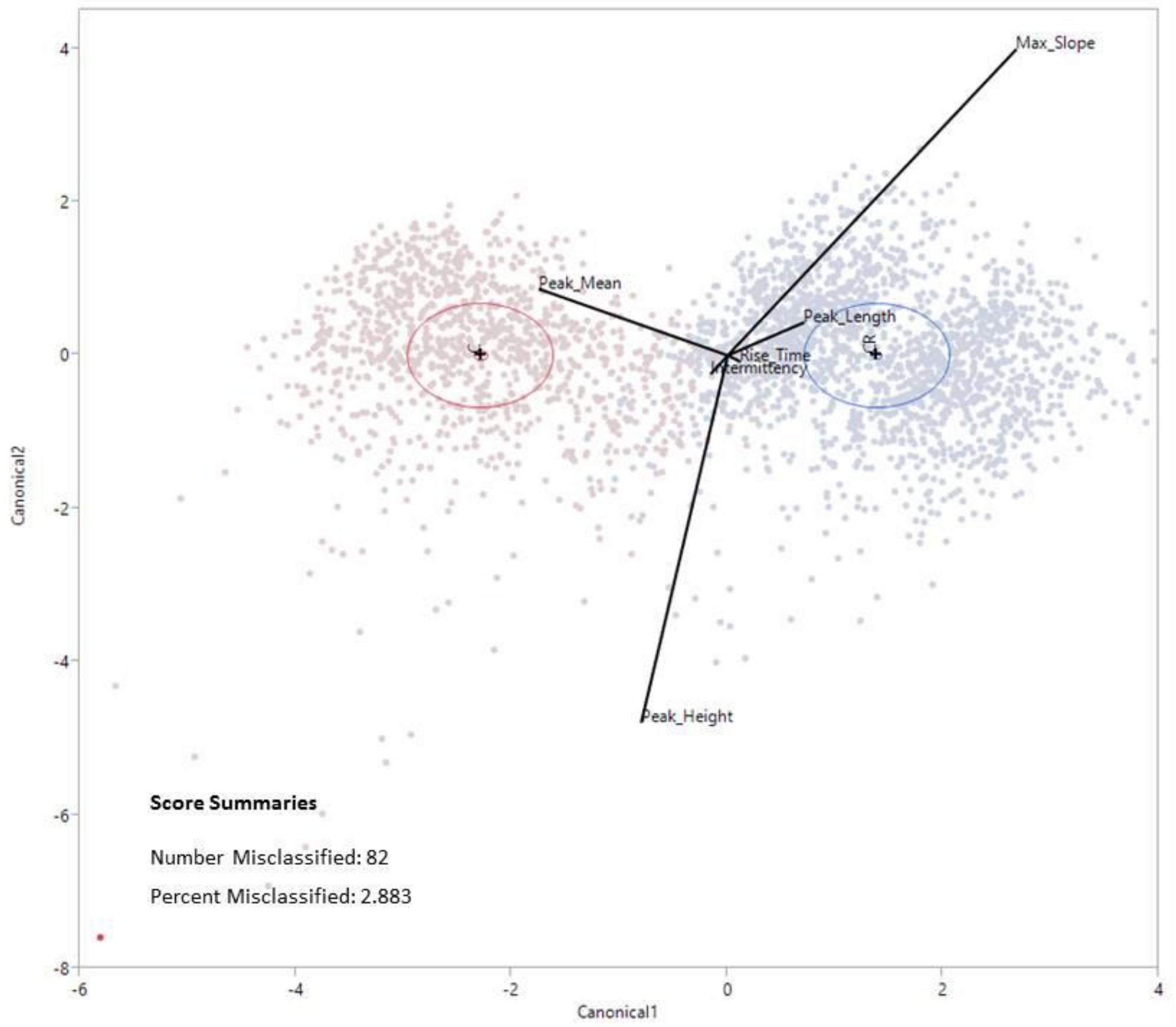

Figure 4. Canonical plot of linear discriminant analysis of extracted peak data from Carp Creek (left, red) and Carp River (right, blue). 

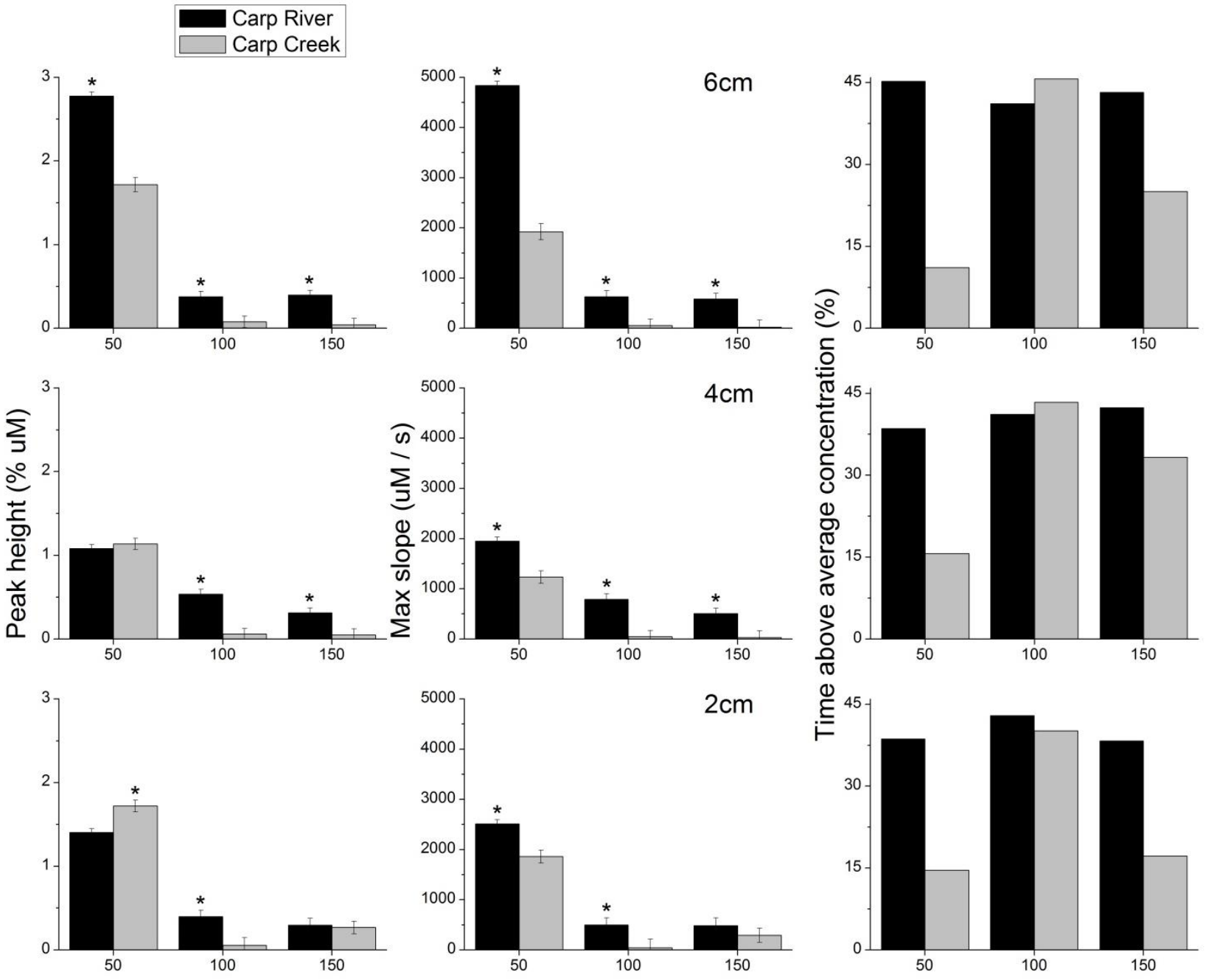

Distance downstream $(\mathrm{cm})$

Figure 5. (columns) Mean standardized peak height, maximum peak slope of pulses measured, and percent time dopamine concentrations rose above the average concentration within each time - series collected at $50 \mathrm{~cm}, 100 \mathrm{~cm}$, and $150 \mathrm{~cm}$ downstream of the input area at $2 \mathrm{~cm}, 4 \mathrm{~cm}$, and $6 \mathrm{~cm}$ (rows) above the cobble and sand substrates of Carp River (black bars) and Carp Creek (gray bars), respectively. A three - way factorial MANOVA with a Fisher LSD post - hoc was utilized to evaluate significant differences (asterisks) at heights and distances across each river. 

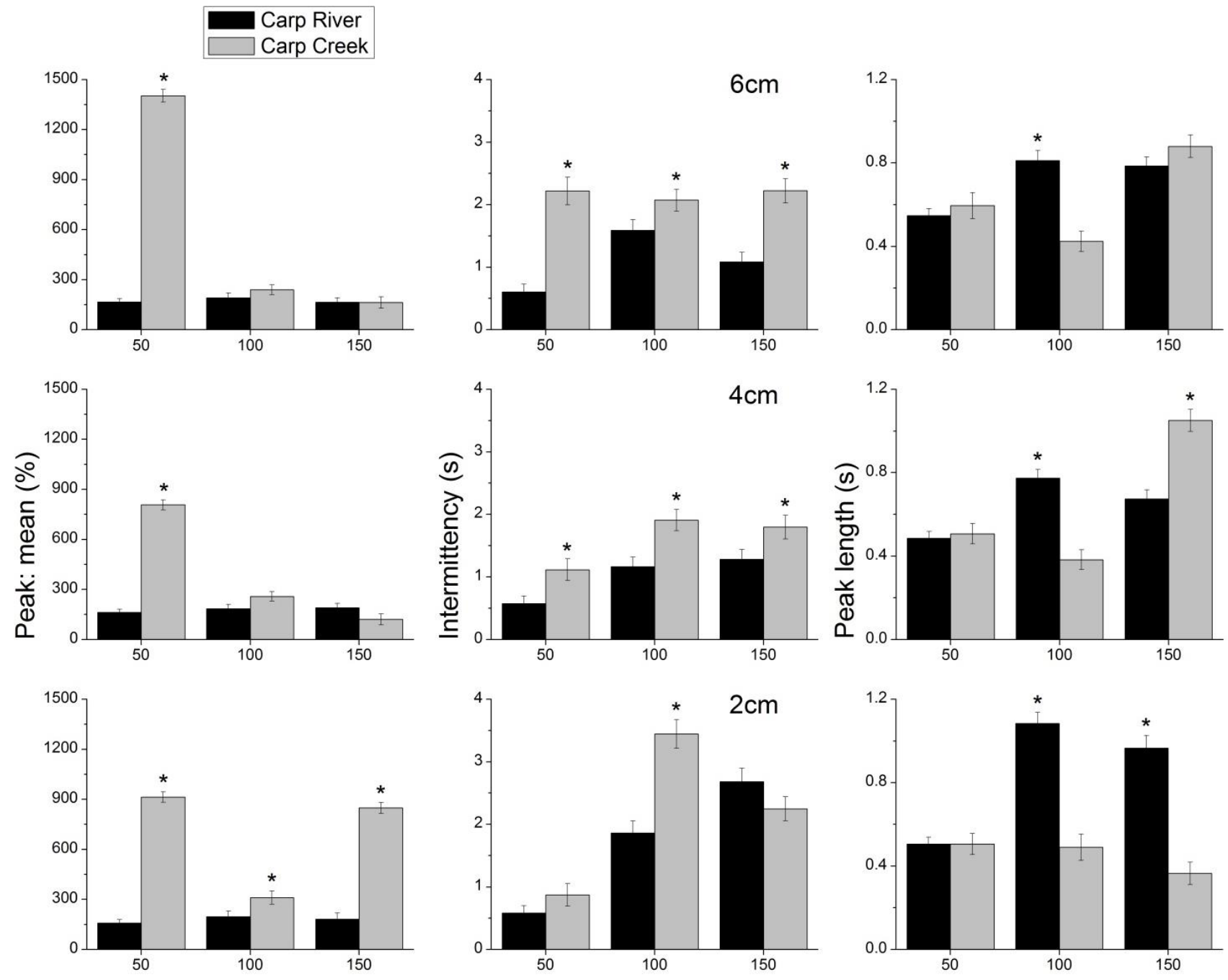

Distance downstream $(\mathrm{cm})$

Figure 6. (columns) Ratio of each chemical pulse to average spectrum concentration, mean intermittency of chemical pulses, and mean peak length measured within each time series at $50 \mathrm{~cm}, 100 \mathrm{~cm}$, and $150 \mathrm{~cm}$ downstream of the input area at $2 \mathrm{~cm}, 4 \mathrm{~cm}$, and 6 $\mathrm{cm}$ (rows) above the cobble and sand substrates of Carp River (black bars) and Carp Creek (gray bars), respectively. A three - way factorial MANOVA with a Fisher LSD post - hoc was utilized to evaluate significant differences (asterisks) at heights and distances across each river. 